\title{
EDITORIAL
}

\section{ILMAC - The Swiss Science and Technology Fair}

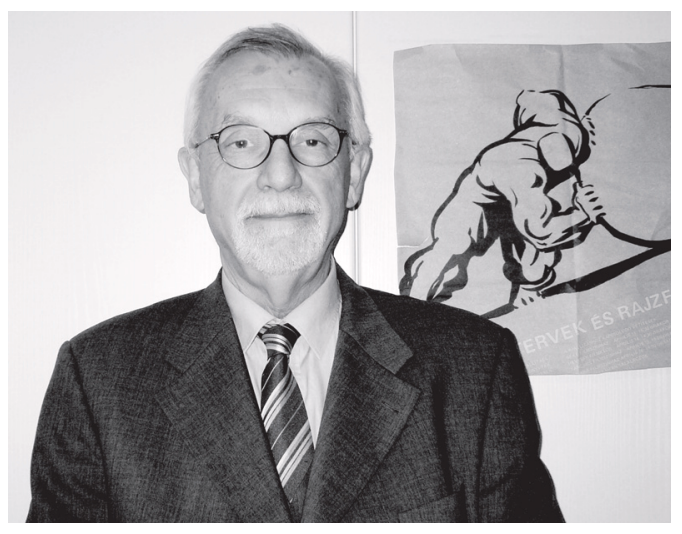

'Is science necessary?' - is the title of an essay by Max F. Perutz. He said yes, and we say yes. In the preface to this collection of essays [1] Perutz writes: "There is little benefit in following scientists' daily grind but much in tracing the unique combination of theoretical knowledge and manual skill, the web of personal encounters and accidental observations, the experience, temperament, moods, and dashes that go into making a discovery, even though the crucial leap of mind is often impenetrable."

You can experience a large part of what is so well said in the sentence above at the ILMAC. In the mornings of four days you listen to science, theoretical knowledge, at its best, four mornings and four different topics; in the afternoon you make yourself acquainted with the software aided manual skills of today presented by more than 450 exhibitors of this technical fair.

And in-between, I am sure, you will have personal encounters. A possibly ideal combination which can lead to discoveries or at least to innovations.

The ILMAC is a must and you have this fantastic program at your doorstep in Basel:

- Tuesday - New Tools in Nanoscience for Biodiagnostics and Bioapplications

- Wednesday - The Fate of Drugs in the Body - Mechanisms and Predictions for Uptake, Distribution and Elimination of Pharmaceuticals

- Thursday - From Proteomics to Systems Biology

- Friday - Trends in Bioanalysis: NMR and MS

There is no question about it - we need science; science is necessary, not only to open a door to 'infinite wisdom' but even more to set a limit to infinite error [2].

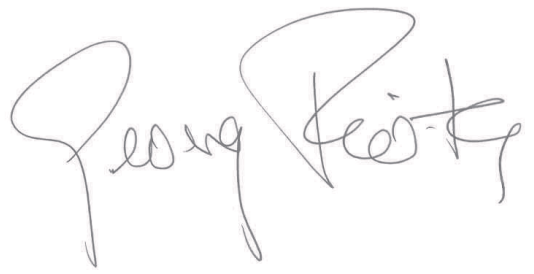

\section{Prof Dr. Georg Fráter}

President of the Swiss Chemical Society (SCS)

[1] M.F. Perutz, 'Is science necessary? Essays on science and scientists', Ed. E.P. Dutton, New York, 1989.

[2] Free after B. Brecht, 'Galileo'. 